\title{
Prevalence of Seropositive Cases among Blood Donors: A 10 Years Retrospective Study in a Tertiary Care Hospital
}

\author{
Dr. VB Prakash ${ }^{1}$, Dr. Navyashree $\mathrm{N}^{2 *}$, Dr. Deepthi $\mathrm{KS}^{3}$
}

\author{
${ }^{1}$ Assistant Professor Department of Pathology Adichunchanagiri Institute of Medical Sciences Adichunchanagiri University, Mandya, Karnataka, India \\ ${ }^{2}$ Resident doctor, Department of Pathology, Karnataka Institute of Medical Sciences, Hubballi Karnataka, India \\ ${ }^{3}$ Consultant Pathologist Blood Bank Officer, St Joseph Hospital, Mysore, Karnataka, India
}

DOI: $\underline{10.36348 / \mathrm{sjpm} .2020 . \mathrm{v} 05 \mathrm{i} 01.009}$

| Received: 03.01.2020 | Accepted: 21.01.2020 | Published: 30.01 .2020

*Corresponding author: Dr. Navyashree $\mathrm{N}$

\section{Abstract}

Due to long term morbidity and mortality associated with transfusion transmissible infections (TTI), the present study was undertaken to find out the prevalence of transfusion transmissible seropositive infections among both voluntary and replacement blood donors over a period of ten years at a tertiary care hospital. Aim: The aim of this study is to determine the seroprevalence of transfusion transmissible infections among blood donors. Material and methods: This is a retrospective study conducted on all voluntary and replacement blood donors in a tertiary care hospital for a period of 10 years from 2010 to 2019. Blood samples were screened for HIV, HBV, HCV by ELISA, for syphilis by rapid plasma reagin test and malarial parasites. All seroreactive blood bags considered as positive for TTIs were discarded. Result: Out of total 18490 donor's blood units screened using standard blood tests for transfusion transmissible infections, replacement donors constituted $26.2 \%$ and $73.8 \%$ were voluntary blood donors. A total of 161 samples $(0.87 \%)$ were found to be positive for TTIs. Seroprevalence of HIV, HBV, HCV and Syphilis was found to be $0.13 \%, 0.62 \%, 0.08 \%$ and $0.02 \%$ respectively. No donors were found positive for malaria parasites. Conclusion: Overall seroprevalence of TTI was $0.87 \%$ with high prevalence of HBV infection when compared to other TTIs. Safe blood transfusion is still a challenge with this prevalence rate. Hence there is a need of more sensitive screening tests especially in screening HBV infection to minimize TTIs along with strict donor selection criteria.

Keywords: Blood donors, seroprevalence, transfusion transmissible infections.

Copyright @ 2020: This is an open-access article distributed under the terms of the Creative Commons Attribution license which permits unrestricted use, distribution, and reproduction in any medium for non-commercial use (NonCommercial, or CC-BY-NC) provided the original author and sources are credited.

\section{INTRODUCTION}

The Indian subcontinent is classified as an intermediate HBV endemic zone (HBs Ag carriage 2$7 \%$ ) and has the second largest global pool of chronic $\mathrm{HBV}$ infections. Indian population has 5.7 million HIV positive, 43 million HBV positive, and 15 million $\mathrm{HCV}$ positive persons [1]. With every unit of blood, there is $1 \%$ chance of transfusion-associated problems including transfusion-transmitted diseases [2]. Though blood transfusion is a therapeutic intervention, it is associated with some risks of transfusion transmissible infections to the recipients especially when blood was collected during window period [3]. Preventing transmission of these infectious diseases through blood transfusion presents one of the greatest challenges of transfusion medicine [4]. In order to curtail this NACO has made mandatory screening tests for Human Immunodeficiency Virus (HIV), Hepatitis B Virus(HBV), Hepatitis C Virus (HCV), Syphilis and Malaria on all donated blood and any unit of whole blood or blood components that test positive should be discarded[5]. With this background we conducted a retrospective study to determine the prevalence of seropositive cases among both voluntary and replacement blood donors in a tertiary care hospital blood bank.

\section{MATERIAL AND METHODS}

Source of data: A 10 years retrospective study was conducted at the blood bank of a tertiary care hospital Adichunchanagiri Institute of Medical Sciences, Bellur, Karnataka. All data were collected from blood bank records from 2010 to 2019.

Sample size: A total 18490 donor's blood units were screened using standard blood tests for transfusion transmissible infections which included 4855 replacement blood donors' and 13635 were voluntary blood donors'. 


\section{INCLUSION CRITERIA}

Healthy voluntary and replacement donors

\section{EXCLUSION CRITERIA}

Blood donors who are unfit to donate blood according to standard blood donor's criteria

\section{METHODS}

All donor samples were screened for

- Hepatitis B surface antigen by HEPALISA. J.Mitra \& co. Pvt. Ltd (microwell ELISA)

- HIV by MICROLISA J.Mitra \& co. Pvt. Ltd (microwell ELISA)

- HCV by MICROLISA J.Mitra \& co. Pvt. Ltd (microwell ELISA)

- $\quad$ Syphilis by RPR test (BEACON diagnostics)

- Malarial parasite by peripheral smear.
All tests were performed according to the manufacturer's guidelines. Reactive samples were repeated in different test with different principle before labelling them seropositive. The donated blood discarded whenever the donor sample was found positive for any TTI.

The statistical analysis was done using the appropriate tests.

\section{RESULTS}

The study analysed a total of 18490 blood donor units screened for HIV, HBV, HCV infection, and syphilis and malaria parasite. Out of that majority, i.e. $73.8 \%$ (13635) were voluntary donors and $26.2 \%$ (4855) were replacement donors. Year-wise distribution of seropositive cases among blood donors showed progressive decline in the seropositive cases. (Table 1, Figure 1).

Table-1: Year-wise distribution of seropositive cases among blood donors

\begin{tabular}{|l|l|l|l|l|l|l|l|}
\hline Year & $\begin{array}{l}\text { Total blood } \\
\text { donation }\end{array}$ & $\begin{array}{l}\text { HIV } \\
\text { infection }\end{array}$ & $\begin{array}{l}\text { HBV } \\
\text { infection }\end{array}$ & $\begin{array}{l}\text { HCV } \\
\text { infection }\end{array}$ & Syphilis & Total & $\begin{array}{l}\text { Seroprevalence } \\
\text { of TTIs }\end{array}$ \\
\hline 2010 & 2126 & 4 & 17 & 0 & 0 & 21 & $\mathbf{0 . 9 8}$ \\
\hline 2011 & 1619 & 4 & 9 & 2 & 2 & 17 & $\mathbf{1 . 0 5}$ \\
\hline 2012 & 1677 & 2 & 13 & 0 & 0 & 15 & $\mathbf{0 . 8 9}$ \\
\hline 2013 & 1781 & 2 & 15 & 3 & 1 & 21 & $\mathbf{1 . 1 7}$ \\
\hline 2014 & 1683 & 5 & 13 & 0 & 0 & 18 & $\mathbf{1 . 0 6}$ \\
\hline 2015 & 1950 & 0 & 13 & 0 & 0 & 13 & $\mathbf{0 . 6 6}$ \\
\hline 2016 & 1783 & 3 & 11 & 6 & 0 & 20 & $\mathbf{1 . 1 2}$ \\
\hline 2017 & 2810 & 3 & 12 & 2 & 0 & 17 & $\mathbf{0 . 6}$ \\
\hline 2018 & 1545 & 1 & 6 & 2 & 0 & 09 & $\mathbf{0 . 5}$ \\
\hline 2019 & 1516 & 1 & 7 & 1 & 1 & 10 & $\mathbf{0 . 6 5}$ \\
\hline Total & $\mathbf{1 8 4 9 0}$ & $\mathbf{2 5}$ & $\mathbf{1 1 6}$ & $\mathbf{1 6}$ & $\mathbf{4}$ & $\mathbf{1 6 1}$ & $\mathbf{0 . 8 7}$ \\
\hline
\end{tabular}

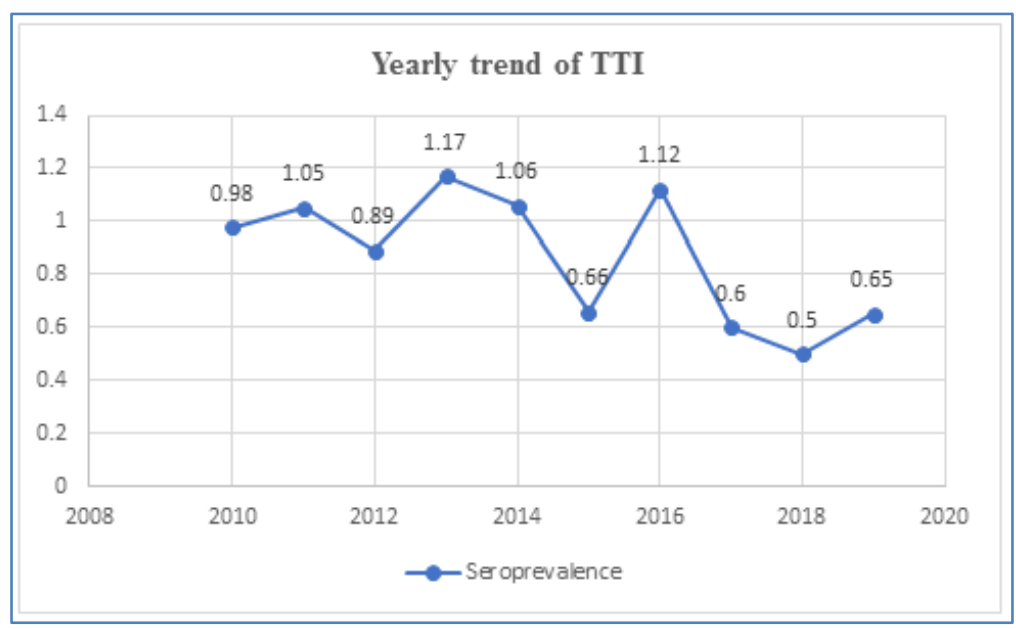

Fig-1: Yearly trend showing seroprevalence of all transfusion transmissible infections

There were 161 seropositive patients with an overall prevalence of $0.87 \%$. Among the seropositive patients 25 were HIV positive, 116 were HBV positive, 16 were $\mathrm{HCV}$ positive and 4 were syphilis with a seroprevalence of $0.13 \%, 0.62 \%, 0.08 \%$ and $0.02 \%$ respectively. No donors were found positive for malaria parasites.

In the percentage distribution of TTI, HBV infection had a major share among both voluntary blood donors and replacement donors (Table 2). 
Table-2: Percentage distribution of TTI in voluntary blood donors and replacement donors

\begin{tabular}{|l|l|l|l|}
\hline TTI & $\begin{array}{l}\text { Number of voluntary } \\
\text { donors }(\boldsymbol{\%})\end{array}$ & $\begin{array}{l}\text { Number of replacement } \\
\text { donors }(\boldsymbol{\%})\end{array}$ & $\begin{array}{l}\text { Total } \\
(\boldsymbol{\%})\end{array}$ \\
\hline HIV & $20(13.9 \%)$ & $5(29.4 \%)$ & 25 \\
\hline HBV & $104(72.2 \%)$ & $12(70.6 \%)$ & 116 \\
\hline HCV & $16(11.1 \%)$ & 0 & 16 \\
\hline Syphilis & $4(2.8 \%)$ & 0 & 4 \\
\hline Total & $\mathbf{1 4 4 ( 1 0 0 \% )}$ & $\mathbf{1 7}(\mathbf{1 0 0 \%})$ & $\mathbf{1 6 1}$ \\
\hline
\end{tabular}

In the present study, out of total 161 positive samples, the majority were positive for hepatitis B infection $116(72 \%)$, followed by HIV infection
25(15.5\%), HCV infection $16(10 \%)$ and syphilis 4 (2.4\%) (Figure 2).

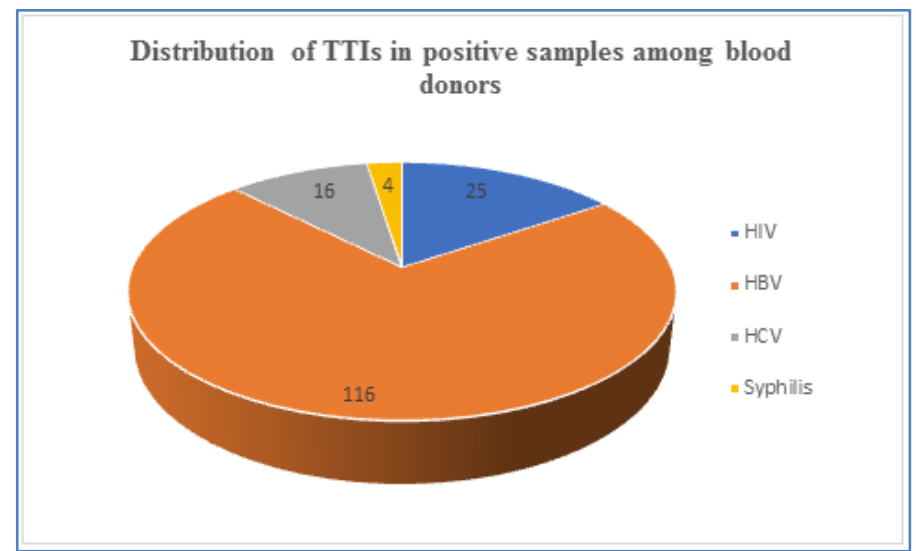

Fig-2: Distribution of various transfusion transmitted infections in positive samples among blood donors

\section{DISCUSSION}

The present study was conducted with the aim to determine the seroprevalance of transfusion transmissible infections among blood donors.

WHO recommends voluntary over replacement blood donation. In the present study, out of 18490 blood donors, $73.8 \%$ (13635) were voluntary donors and $26.2 \%$ (4855) were replacement donors, which is similar to the study done by Ahmed $\mathrm{K}$ et al. [1], Sehgal S et al. [6] and Soumya TS et al.[7] All these studies had major percentage of voluntary blood donors. Increase in voluntary donation may be due to propagation of voluntary blood donation by National AIDS Control Organization (NACO), Non-Government Organizations and also due to increasing public awareness. But studies conducted by Makroo, et al. [8] and Arora et al. [9] had major contribution from replacement blood donation. Hence it is essential to create awareness among people regarding benefits of voluntary blood donation and encourage becoming voluntary blood donors.

Out of 18490 donor's blood units screened, $161(0.87 \%)$ blood units were positive for TTI. It is almost similar to the study conducted by Lathamani, et al. [10] which was $0.82 \%$. Studies conducted by Soumya TS et al. [7] (0.94\%), Ahmed K, et al. [1] (1.4\%) and Sehgal S et al. [6] (2.18\%) showed higher prevalence of TTIs as compared to the present study. This difference may be due to strict donor selection criteria in the present study which led healthy donors to donate blood.

In the present study overall seroprevalence of $\mathrm{HIV}, \mathrm{HBV}, \mathrm{HCV}$ and syphilis was $0.13 \%, 0.62 \%$, $0.08 \%$ and $0.02 \%$ respectively. Seroprevalence of hepatitis B infection was highest among all the TTI.

Lathamani et al. [10] in their study found prevalence of $\mathrm{HIV}$ as $0.08 \%, \mathrm{HBV}$ as $0.5 \%, \mathrm{HCV}$ as $0.09 \%$, and syphilis as $0.09 \%$.

Jashim, et al. [11] in Bangladesh, found the prevalence of $\mathrm{HIV}$ as $0.135 \%$, $\mathrm{HBV}$ as $1.4 \%$, $\mathrm{HCV}$ as $0.13 \%$, and syphilis as $0.46 \%$.

Ahmed K et al. [1] found prevalence of HBV, $\mathrm{HIV}, \mathrm{HCV}$, and Syphilis to be $1.06 \%, 0.2 \%, 0.14 \%$, and $0.05 \%$, respectively.

Study by Shah, et al. [12] seroprevalence of HIV, HBV, HCV, and syphilis was found to be $0.15 \%$, $0.9 \%, 0.1 \%$, and $0.2 \%$, respectively.

In all these studies prevalence of $\mathrm{HBV}$ infection was high in comparison with other TTIs, which is similar to the observation of the present study.

In India, transfusion associated HBV infection was estimated to be approximately $50 \%$ or more in patients who have received a multiple transfusion. They 
found that in apparently healthy individuals absence of HBsAg in the blood may not be sufficient to ensure lack of circulating HBV. Blood containing anti-HBc antibodies with or without detectable presence of HBsAg might be infectious. They suggest that routine anti-HBc screening of blood donations could prevent some transfusion transmitted HBV infections [13]. This significant increasing trend in $\mathrm{HBV}$ infection can be controlled by using strict aseptic conditions in all procedures involving contact with blood and blood products.

In the present study, no donors were found positive for malaria parasites. This finding is same as that observed by Srikrishna et al. [4], Sonawone et al. [14], Farnandez et al. [15] and Pallavi et al. [16]. This observation may be due to the result of considering peripheral blood smear for screening which is less sensitive technique as it requires presence of at least 100 parasites $/ \mu \mathrm{l}$ of blood to be detected microscopically. Hence more sensitive technique has to be incorporated to avoid post transfusion malaria.

\section{CONCLUSIONS}

Out of 18490 healthy donor samples, 161 cases screened positive with prevalence of $0.87 \%$. Voluntary donors form the majority $73.8 \%$ in the present study; this shows awareness in the population about voluntary blood donation. Overall prevalence of HIV, HBV, HCV, and Syphilis was $0.13 \%, 0.62 \%$, $0.08 \%$, and $0.02 \%$ respectively showing high $\mathrm{HBV}$ prevalence. Safe blood transfusion is still a challenge with these prevalence rates. Hence there is a need of more sensitive screening tests especially in screening HBV infection to minimize TTIs along with strict donor selection criteria. And also encouraging healthy voluntary blood donors to continue the practice of donation.

\section{REFERENCES}

1. Ahmed, K., Shoba, K.L., Sumangala, B., Samaga, M.P., Akshantha, B.S., Shetty, N.S.(2015). Seroprevalence of Human Immunodeficiency Virus, Hepatitis B Virus, Hepatitis C Virus, and Syphilis in Blood Donors at District Level Blood Bank in a Teaching Hospital, Mandya, Karnataka. Int J Sci Stud, 3(7):76-81.

2. Widmann, F.K. (1985). Editor. Technical Manual American Association of Blood Banks. $9^{\text {th }} \mathrm{ed}$. Aglington, Virginia: Karger Publicishers, 325-44.

3. Fleming, A.F. (1997). HIV and blood transfusion in sub-Saharan Africa. Transfus Sci, 18:167-79.

4. Srikrishna., Sitalaxmi, S., Domodhar, P. (1999). How safe are our safe blood donors. Indian J Pathol Microbial, 42:411-6.

5. Price, T. H. (2008). Standards for Blood Banks and Blood Transfusion Services.
6. Sehgal, S., Shaiji, P. S., \& BRaR, R. K. (2017). Seroprevalence and trends of transfusion transmissible infections in blood donors in Andaman and Nicobar Islands-an institutional retrospective study. Journal of clinical and diagnostic research: JCDR, 11(4), EC21.

7. Sowmya, T.S., Purushottam, R., Naik, H.K.(2017). Impact of IDNAT on blood safety; a retrospective study on prevalence of infectious markers and their trends among blood donors at a tertiary care hospital. Indian Journal of Pathology: Research and Practice. 6(2):312-7.

8. Makroo, R.N., Salil, P., Vashist, R.P., Shivlal. (1996). Trends of HIV infection in the blood donors of Delhi. Indian J Pathol Microbiol; 39:13942.

9. Arora, D., Arora, B., Khetarpal, A. (2010). Seroprevalence of HIV, HBV, HCV and syphilis in blood donors in Southern Haryana. Indian J Pathol Microbiol; 53:308-9.

10. Lathamani, K., Bhaktha, G., Nayak, S., Kotigadde, S. (2013). Prevalence of HIV, HCV, HBV and syphilis in blood donors among the Dakshina Kannada District, India. Int J Curr Microbiol App Sci; 2:249-52

11. Jashim, M.U., Sanjoy, K.D., Suhrawardy, S.M., Moynal, H., Pranab, C.(2012). Outcome of screening test performed on volunteer blood donors in Chittagong city. Int J Sci Eng Res,3:1-9

12. Shah, N., Shah, J.M., Jhaveri, P., Patel, K., Shah, C.K., Shah, N.R. (2013). Sero prevalence of HBV, $\mathrm{HCV}, \mathrm{HIV}$ and syphilis among blood donors at a tertiary care teaching hospital in Western India. Gujarat Med J; 68:35-9.

13. Bhattacharya, P., Chandra, P.K., Datta, S., Banerjee, A., Chakraborty, S., Rajendran, K. (2007). Significant increase in HBV, HCV, HIV and syphilis infections among blood donors in West Bengal, Eastern India 2004-2005: Exploratory screening reveals high frequency of occult HBV infection. World J Gastroenterol; 13:3730-3.

14. Sonawane, B.R., Birare, S.D., Kulkarni, P.V.(2003). Prevalence of seroreactivity among blood donors in rural population. Indian J Med Sci; 57:405-7.

15. Farnandez, H., D’Souza, P.F., D’Souza, P.M. (2010). Prevalence of transfusion transmitted infections in voluntary and replacement donors. Indian J Hematol Blood Transfusion, 26(3):89-91.

16. Pallavi, P., Ganesh, C.K., Jayashree, K., Manjunath, G.V. (2011). Seroprevalence and trends in transfusion transmitted infections among blood donors in a University hospital Blood Bank: A 5 year study. Indian J Hematol, Blood Transfus, 27(1):1-6. 